\title{
Anthelmintic resistance of horse strongyle nematodes to ivermectin and pyrantel in Lithuania
}

Evelina Dauparaite ${ }^{1 *}$, Tomas Kupčinskas ${ }^{1}$, Georg von Samson-Himmelstjerna ${ }^{2}$ and Saulius Petkevičius ${ }^{1}$

\begin{abstract}
Background: With intensive use of anthelmintic drugs in recent decades, anthelmintic resistance (AR) in horse nematodes is becoming a growing issue in many countries. However, there is little available information about the parasites, treatment practices or AR in the horse population in Lithuania. The aim of this study was to assess the current situation of AR on horse farms in Lithuania. The study was conducted in 25 stables on horses with a strongyle faecal egg count (FEC) of $\geq 200$ eggs per gram. A faecal egg count reduction test (FECRT) was performed on each farm after administration of ivermectin (IVM) or pyrantel (PYR).

Results: The efficacy of IVM was comparatively high, with $98.8 \%$ of 250 horses having a zero egg count 14 days after treatment. Two conditions were used to interpret the FECRT results for PYR: firstly, resistance was determined when FECR was $<90 \%$ and the lower $95 \%$ confidence interval $(\mathrm{LCL})$ was $<80 \%$, and secondly when in addition the upper confidence level (UCL) was $<95 \%$. Under the first condition, resistance against PYR was found in five stables (25\% of all tested herds), while when considering the UCL as well, resistance was only detected in two stables (8\%). The FEC showed a significant $(\mathrm{P}<0.01)$ difference between the treatment and control groups. Only cyathostomin larvae were detected in larval cultures derived from strongyle-positive faecal samples collected 14 days after treatment of a test group with PYR.
\end{abstract}

Conclusions: This in vivo study showed that PYR resistance is prevalent on horse farms in Lithuania, while the efficacy of IVM still appears to be unaffected. However, further studies of ivermectin resistance are needed. These findings should guide the implementation of more sustainable management of strongyle infections in horses in Lithuania.

Keywords: Efficacy, Helminths, In vivo, Selective therapy

\section{Background}

Strongylid (family Strongylidae) nematodes, such as Strongylus (large strongyles) and cyathostomins (small strongyles), are the main internal nematode parasites of horses and constitute more than $75 \%$ of the total intestinal parasite fauna $[1,2]$. Large strongyles, such as the highly pathogenic Strongylus vulgaris, are no longer

\footnotetext{
*Correspondence: evelina.dauparaite@lsmu.lt

1 Laboratory for Parasitology, Department of Veterinary Pathobiology,

Veterinary Academy, Lithuanian University of Health Sciences, Tilzes str.

18, 47181 Kaunas, Lithuania

Full list of author information is available at the end of the article
}

commonly found in domestic horses [3, 4]. This has led to a shift in the focus of anthelmintic treatment programmes to the less pathogenic, but more common and abundant cyathostomin parasites $[5,6]$.

The increased resistance of horse nematodes to anthelmintic drugs [7] is a matter of concern all over the world. The use of uncritical anthelmintic treatment strategies rather than evidence-based treatments may partly explain the apparent increase in reports of resistance [5]. Resistance to benzimidazole has been reported all over the world [8-11], while resistance to pyrantel (PYR) is emerging in the USA, UK, Germany and Italy [12-14]. 
In other European countries close to Lithuania, the situation regarding resistance to benzimidazole and pyrantel is fairly similar. Resistance to benzimidazole has been reported in Poland [15] and Ukraine [16], and resistance to pyrantel has been reported in Estonia [17] and Sweden [18]. The last time resistance to benzimidazole was confirmed in Lithuania was by Vyšniauskas et al. [19]. Due to the appearance of resistance to these two drug classes, in the past two decades great reliance has been placed on macrocyclic lactones (ML). Reports from France [20], Germany [21], Belgium, the Netherlands [22] and the UK [23] have revealed a shortened strongyle egg reappearance period (ERP) after treatment with ivermectin or moxidectin, which is interpreted as an early indication of emerging resistance. The current status of anthelmintic efficacy in domestic horses is of importance for both scientists, veterinarians and horse owners, particularly because no new drug classes or modes of action have been introduced since ivermectin in the 1980s [24].

It is widely accepted that due consideration of the role of parasite refugia is key to preserving the efficacy of anthelmintic drugs in worm control programmes [25]. One way to maximise refugia is to apply selective targeted treatment as part of a sustainable equine nematode control programme [26]. For worm control in adult horses, guidelines from the European Scientific Counsel Companion Animal Parasites (ESCCAP) and the American Association of Equine Practitioners (AAEP) recommend using FEC for surveillance, based on anthelmintic treatment programmes in which only those horses above an arbitrary cut-off of typically $\geq 200$ eggs per gram (FEC) are treated $[6,27]$. Alternatively, for adult horses where selective treatments are not feasible and particularly concerning worm control in young horses, ESCCAP guidelines for strategic treatments aim to reduce treatment frequencies and vary the drug classes [27]. To ensure this can happen, it is important to have information on the actual drug efficacy, which should be regularly assessed on each farm by post-treatment efficacy testing.

The widely used test to assess anthelmintic efficacy is the in vivo FECRT. The World Association for the Advancement of Veterinary Parasitology (WAAVP) has issued guidelines for the procedure and calculation of FECRT [28]. However, there is no single agreed interpretation of the outcome of FECRT and different recommendations have been made to classify drug efficacy as "resistance" or "susceptible", thus the results obtained in different studies cannot always be compared directly [7]. WAAVP's current recommendations advise considering the presence of resistance if, firstly, the FECR is $<90 \%$ and secondly the $95 \%$ lower confidence level (LCL) is $<90 \%$. Resistance is deemed 'possible' if one of the two conditions is met. This accounts for BZ and IVM in sheep and goats. For BZ in horses, the cut-off point is set at FECR $<90 \%$ but no LCL value is given [28]. More recently, Lyndal-Murphy et al. [29] have shown that it is important to include the 95\% upper confidence limit (UCL) when classifying FECRT results and that the presence of resistance can only be confirmed if the UCL is $<95 \%$.

Lithuania is estimated to have a horse population of about 15,800 individuals (Lithuanian Animal Registry Centre) and these horses travel widely. However, there is little information in the Baltic region about anthelmintic resistance (AR). There have been very few equine parasitology surveys conducted in Lithuania-the last study involving equine AR in Lithuania was published more than fourteen years ago [19]. As a result, very litthe is known about the anthelmintic efficacy status of the various formulations available. Therefore, the aim of this study was to provide further information about the observed efficacy of frequently used formulations of ivermectin and pyrantel against populations of strongylid parasites on horse farms in Lithuania.

\section{Methods}

The study was carried out between April and November 2019 in twenty-five stables in the northern (44\%), central (28\%), western (16\%) and eastern (12\%) regions of Lithuania. Horses on these farms are used for sport, leisure riding and breeding.

In order to find comparable results, larger stud farms, i.e. with at least 35 horses, were pre-selected from the database of the Lithuanian Equestrian Federation (LEF) [30]. The initial screening included 707 horses, and further studies were performed on the horses that met the inclusion criteria, which were strongyle faecal egg counts exceeding 200 eggs per gram (EPG). All horses had access to pasture and had not received any antiparasitic treatment in the eight weeks prior to the study. A total of 659 horses met these inclusion criteria.

Faecal samples were analysed quantitatively using a modified McMaster technique with a detection threshold of 20 EPG [31]. Fresh faecal samples were collected from a pen containing one horse within one hour of defecation or by rectal extraction, and these were stored at $4{ }^{\circ} \mathrm{C}$ and processed within $24 \mathrm{~h}$.

Faecal egg count reduction tests (FECRT) were performed on the 659 horses that met the inclusion criteria. The efficacy of both drugs was evaluated in accordance with the recommendations of the World Association for the Advancement of Veterinary Parasitology (WAAVP). Anthelmintic resistance in horses was determined as the percentage reduction of mean egg counts at 14 days posttreatment: $\mathrm{FECR} \%=100 \times(1-(\mathrm{X} 1 / \mathrm{X} 2)(\mathrm{Y} 1 / \mathrm{Y} 2)$, where $\mathrm{X} 1$ and $\mathrm{X} 2$ represent the mean pre-treatment and posttreatment faecal nematode egg counts (FECs) of a treated 
group, and $\mathrm{Y} 1$ and $\mathrm{Y} 2$ represent the mean pre-treatment and post-treatment FECs of an untreated control group respectively [28]. On each farm, the horses selected for testing were randomly assigned to three experimental groups: group A was treated with IVM $(n=10)$, group B with PYR $(n=10)$ and group $C$ was the untreated control group $(n \geq 5)$. The numbers of animals in the respective treatment groups were based on the recommendation that 10 animals per group are considered sufficient to detect differences in FEC between groups [28].

The weight of each animal was estimated using a girth measuring tape. The anthelmintic dosages and routes of application were in accordance with the drug manufacturers' recommendations. IVM $(0.2 \mathrm{mg}$ per $\mathrm{kg}$ body weight) was administered per os using the product Bimectin $^{\circledR}$ (Cross Vetpharm Limited, Ireland) and PYR embonate (19 mg per kg body weight) was administered per os using the product Embotape ${ }^{\circledR}$ (Cross Vetpharm Limited, Ireland).

\section{FECR was classified using two different sets of methods}

Assessment method 1 classified the results as "no resistance", "suspected resistance" and "confirmed resistance" using the observed FECR and LCL, according to the WAAVP recommendations [28], which for cattle considers FECR of $<95 \%$ with a $95 \% \mathrm{LCL}$ of $<90 \%$ as "confirmed resistance", while a result where only one of the two criteria is met is considered as "suspected resistance". These recommendations propose a value of $<90 \%$ as being indicative of resistance in horses, but give no value for the $95 \%$ LCL. Hence, in line with other recent equine AR studies [13, 32], the cut off was set at 90\% FECR and the $95 \% \mathrm{LCL}$ was set at $80 \%$ in this study.

Assessment method 2 used a method similar to that advocated by Lyndal-Murphy et al. [29], classifying the parasites as "resistant", "inconclusive" or "susceptible" based on the following conditions: they were "resistant" if the observed FECR is below $90 \%$, LCL is below $80 \%$ and UCL is below 95\%, "susceptible" if the observed FECR is at/above $90 \%$ and LCL is at/above $80 \%$, and "inconclusive" if none of the conditions are met.

\section{Differentiation of third-stage larvae}

Faecal samples collected on each farm on day 14 were pooled and processed for coproculture. A minimum of $3 \mathrm{~g}$ from each strongyle-positive sample were mixed together and incubated for 7 days at room temperature in the laboratory $\left(24-29{ }^{\circ} \mathrm{C}\right.$ ) (adding water to maintain an adequate moisture level and $4 \mathrm{~g}$ of vermiculite). Thirdstage larvae $\left(\mathrm{L}_{3}\right)$ were subsequently recovered from the coprocultures using the Baermann technique [33]. The $\mathrm{L}_{3}$ larvae were microscopically examined, differentiated by morphology characteristics, and identified according to Maff [34]. The first $100 \mathrm{~L}_{3}$ larvae, or all $\mathrm{L}_{3}$ when $\leq 100$ developed $L_{3}$ larvae, were identified per sample. They were identified by the number, shape and arrangement of intestinal cells [35].

\section{Statistical analysis}

Data were analysed using the statistical software package "SPSS for Windows version 20" and descriptive statistics (means, standard deviations, reduction percentages etc.) were calculated. ANOVA was used to compare the mean EPG of each experimental group. Calculation of the arithmetic mean, the percentage of reduction, the $95 \%$ upper and lower confidence limits, and interpretation of the findings was as described by Coles et al. [28]. A probability $(\mathrm{P})$ value less than 0.05 was used to determine the level of significance.

\section{Results}

A total number of 707 horses from 25 farms in Lithuania were coprologically examined in 2019. Of these, 659 horses were used to determine prevalences.

The mean pre-treatment and post-treatment FEC, the FECR percentage and the lower and upper $95 \%$ confidence limits for each group of anthelmintic drugs tested are summarised in Additional file 1.

On three of the 25 farms (12\%), the FECR in the IVM and PYR groups was $100 \%$.

\section{Faecal egg count reduction test with ivermectin}

A total of 250 horses were treated with IVM and 156 horses were left untreated as a control group. On 22 of the 25 farms (88\%), the FECR was $100 \%$ after treatment, and all the horses in this treatment group had a zero egg count on the second visit. Three farms had at least one horse with positive egg count of 20 EPG on day 14. The FECR on these farms was 99.9\% (LCL 99.5\%), 99.9\% (LCL 99.7\%) and 99.7\% (LCL 98.6\%) respectively. IVM-treated horses had significantly $(\mathrm{P}<0.01)$ lower egg counts than the untreated group 14 days after treatment.

\section{Faecal egg count reduction test with pyrantel embonate} A total of 250 horses were treated with PYR and 156 horses were left untreated as a control group. On three of the 25 farms (12\%) the FECR was $100 \%$, and on five farms (20\%) the FECR was $<90 \%$ (See Additional file 1). PYRtreated horses had a lower egg count $(\mathrm{P}<0.01)$ than the untreated horses 14 days after treatment.

\section{Interpretation of FECR and $95 \% \mathrm{Cl}$ based on the different assessment methods}

With the IVM results assessment by methods 1 and 2, both methods confirmed that 'no resistance' to IVM was found on the 25 (100\%) farms (Table 1$)$. 


\begin{tabular}{|c|c|c|c|c|}
\hline Drug class & Method No. 1 & $\begin{array}{l}\text { Horse } \\
\text { stud } \\
\text { farms }\end{array}$ & Method No. 2 & $\begin{array}{l}\text { Horse } \\
\text { stud } \\
\text { farms }\end{array}$ \\
\hline \multirow[t]{3}{*}{ IVM } & $\begin{array}{l}\text { Confirmed resist- } \\
\text { ance }\end{array}$ & 0 & Resistant & 0 \\
\hline & $\begin{array}{l}\text { Suspected resist- } \\
\text { ance }\end{array}$ & 0 & Susceptible & 10 \\
\hline & No resistance & 25 & Inconclusive & 25 \\
\hline \multirow[t]{3}{*}{ PYR } & $\begin{array}{l}\text { Confirmed resist- } \\
\text { ance }\end{array}$ & 5 & Resistant & 2 \\
\hline & $\begin{array}{l}\text { Suspected resist- } \\
\text { ance }\end{array}$ & 1 & Susceptible & 16 \\
\hline & No resistance & 19 & Inconclusive & 7 \\
\hline
\end{tabular}

PYR, pyrantel, IVM, ivermectin

With the PYR results assessment by method 1, 'confirmed resistance' to PYR was found on five farms (25\%), 'suspected resistance' was found on one farm (4\%), and 'no resistance' was found on 19 farms (79\%). Assessing the results by method 2, two out of the 25 (8\%) farms were classified as 'resistant', sixteen farms (64\%) as 'susceptible', and seven farms (28\%) as 'inconclusive' (Table 1).

All the third-stage larvae isolated from strongyle egg positive faecal samples were identified as cyathostomin larvae.

\section{Discussion}

Control of equine nematodes has relied on benzimidazoles (BZ), tetrahydropyrimidines and macrocyclic lactones. The intensive use of anthelmintics has led to the development of AR in equine cyathostomins around the world [36]. Monitoring of AR in cyathostomin is one of the most important topics in equine parasitology, but the last study about equine AR in Lithuania was published more than fourteen years ago [19].

Of all the screened candidates $(n=707), 93 \%$ exceeded the value of 200 strongyle EPG, which is considered the treatment threshold in most current recommendations concerning selective treatment strategies. One of the basic principles of selective anthelmintic treatment is a consistency of the relative magnitude of strongyle FEC of individual horses over time [37, 38]. Therefore, identification of high egg shedders within the herd is an essential goal [38-40]. It is proposed that the identification of animals regarded as 'high egg shedders' enables farms and studs to implement more targeted and/or selective treatment approaches to helminth control $[38,40]$. It is known that acquisition of information about natural distribution patterns will help establish appropriate FEC thresholds at which horses should be treated with an effective anthelmintic (commonly quoted as 200-250 EPG) [5, 38].

This would achieve the dual goal of controlling induced health problems while simultaneously reducing pasture contamination [14]. The analysis of the screening FEC data pre-FECRT (not shown) in the present survey demonstrated that there was a higher percentage of "high egg shedders" (i.e. > 200 EPG) than "low or null egg shedders" (i.e. $<200$ EPG), thus confirming that current control programmes are not ideal and providing further support for the value of conducting FECs before planning any anthelmintic treatment in a yard. Leaving a proportion of horses untreated would maximise the refugia with little impact on overall control, as horses with low egg counts are not important sources of environmental contamination. Additionally, egg shedding from untreated animals would dilute the presence on the pasture of any eggs shed by treated animals possibly infected with resistant populations. In this way, the selection pressure would be progressively reduced $[12,14]$.

This study demonstrated a very high efficacy of IVM on reducing helminths in horses in Lithuania. As expected, the mean percentage efficacy of IVM in eliminating strongyle eggs from animal faeces ranged from $99.7 \%$ to $100 \%$ (by FECR) for IVM on all stud farms. On three of the 25 farms, FEC $\geq 20$ EPG 14 days after treatment, but the FECR still indicated a high susceptibility to the drug. Comparable results have been described in a Lithuanian report in 2006 [19], where a 100\% efficacy of IVM against strongyle was shown in a group of ten study horses. In Estonian investigations, FECR after treating horses with IVM was $100 \%$ [17], 100\% in Latvia [41], 99.9\% in Poland [42] and 99\% in Sweden [18]. However, there have been few reports describing incidences of reduced efficacy of IVM against cyathostomin nematodes [14, 43, 44]. Indications of shortened ERP have been found in Germany [21], Belgium, the Netherlands [22] and Finland [45]. Furthermore, findings repeatedly suggest emerging ML resistance in cyathostomins due to reduced ERP following IVM and moxidectin treatments [21, 22, 46]. The shortened ERPs following IVM and moxidectin treatments have been associated with emerging ML resistance by fourth-stage larvae [47]. While resistance to these drugs is still not prevalent, proper use of the drugs via selective treatment using FEC and continued monitoring of efficacy with FECRT is of major importance in slowing down the development process of resistance in equine gastrointestinal parasites.

Field studies indicate that PYR resistance is widespread in equine intestinal nematodes in Europe and other regions. Previous studies have already shown that cyathostomin populations resistant to PYR are present in 
the southern USA, with over $40 \%$ of farms demonstrating resistance to this drug [12]. Furthermore, resistance to PYR has been proven in two out of sixteen farms in Italy (12.5\%) and suspected in one case (6.2\%), with FECR values ranging from $43 \%$ to $85.4 \%$ [48]. Strongyles have been found to be resistant to pyrantel in Finland (43\%), indicating widespread resistance [45]. Geographically near Lithuania, PYR-resistant populations of cyathostomins have been found on Swedish horse farms, but the overall efficacy of PYR is still considered acceptable [18]. Lassen et al. [17] have reported resistance to PYR in Estonia, with FECR of approximately $88 \%$ on four horse farms. These results are consistent with those found in this study. Resistance to PYR was detected on five farms (19\%), with FECR calculated and interpreted in line with WAAVP recommendations. However, horses from only two of the five farms were still interpreted as having "resistance", as recommended by Lyndal-Murphy et al. [29]. Cyathostomins were detected in larval cultures derived from strongyle positive faecal samples collected 14 days after treatment with PYR. It should be noted that Pyrantel embonate (European Pharmacopeia) is considered synonymous with pyrantel pamoate (U.S. Pharmacopeia). The label indications of these two pyrantel salts are virtually interchangeable at the same concentrations and dosages. In the USA, pyrantel pamoate is approved as a broad-spectrum equine anthelmintic at a dosage of $6.6 \mathrm{mg} / \mathrm{kg}$. However, certain formulations made by specific sponsors are also labelled for efficacy against equine tapeworms (Anoplocephala perfoliata) at a " $3 \mathrm{X}$ " dosage of $19.8 \mathrm{mg} / \mathrm{kg}$. This number is close to the pyrantel dosage $(19 \mathrm{mg} / \mathrm{kg})$ cited in the manuscript, and the product name (Embotape) suggests that this formulation is labelled for efficacy against nematodes and tapeworms in horses. The doses in this study were based on the recommendations of the European Pharmacopoeia and the dosages given in the package leaflet, but a dose of $6.6 \mathrm{mg} / \mathrm{kg}$ should be considered in future because the actual pyrantel resistance situation in Lithuania could be significantly higher than that established in the present study.

This in vivo study showed that horse farms in Lithuania are already facing problems with AR, especially resistance to PYR. Despite the fact that resistance was found on five farms and in a small number of horses, an increase in AR can be expected in future. This demonstrates the need for regular parasite and anthelmintic susceptibility monitoring and also the implementation of measures that would delay further development of AR on horse farms.

Infection followed by the development of AR can be controlled by correct administration of anthelmintic substances and a reduction in treatment frequency, e.g. by employing strict pasture management, as well as stable hygiene and farm management. For example, regular removal of manure from the pastures and systematic rotation of horses in paddocks and pens is recommended [49]. Yearly coprological examination is recommended to assess the quality and intensity of infection, as well as the efficacy of the management procedures [7].

\section{Conclusions}

The results of the FECRT with PYR revealed conclusive evidence of the presence of resistant cyathostomins on five farms (19\%). As only very few horses were found to shed eggs 14 days after treatment, the efficacy of IVM was found to be very high on the Lithuanian horse farms studied. While resistance to IVM was not detected and PYR is not yet prevalent, the correct use of antihelmintic drug applications and continued monitoring of efficacy with FECRT is important for slowing down the development $\mathrm{AR}$ in equine gastrointestinal parasites.

\section{Supplementary information}

The online version contains supplementary material available at https://doi. org/10.1186/s13028-021-00569-z.

Additional file 1. The mean pre-treatment and post-treatment faecal egg count, faecal egg count reduction percentage, and lower and upper 95\% confidence limits for each group of anthelmintic drugs tested.

\section{Acknowledgements}

Not applicable.

Prior publication

Data have not been published previously.

\section{Authors' contributions}

SP and TK contributed to the conception and design of the study. ED participated in the design of the study and in the faecal egg count test and was a major contributor to writing the manuscript. GvSH commented on the structure of the manuscript and provided critical intellectual input. All the authors participated in the subsequent discussions and revisions of the entire text. All authors read and approved the final manuscript.

\section{Funding}

This research did not receive any specific grant from funding agencies in the public or not-for-profit sectors. This research was supported by the Science Foundation, Lithuanian University of Health Sciences by donating anthelmintic drugs for research.

\section{Availability of data and materials}

The datasets used and/or analysed during the current study are available from the corresponding author on reasonable request.

\section{Ethics approval and consent to participate}

This study did not require official or institutional ethical approval. The animals were handled according to high ethical standards and national legislation.

\section{Competing interests}

The authors declare that they have no competing interests.

\section{Author details}

${ }^{1}$ Laboratory for Parasitology, Department of Veterinary Pathobiology, Veterinary Academy, Lithuanian University of Health Sciences, Tilzes str. 18 47181 Kaunas, Lithuania. ${ }^{2}$ Institute for Parasitology and Tropical Veterinary 
Medicine, Free University of Berlin, Robert-von-Ostertag Strasse 7-13, 14163 Berlin, Germany.

Received: 14 October 2020 Accepted: 8 January 2021

Published online: 25 January 2021

\section{References}

1. Bucknell D, Hoste H, Gasser RB, Beveridge I. The structure of the community of strongyloid nematodes of domestic equids. J Helminthol. 1996;70:185-92.

2. Lichtenfels JR, Kharchenko VA, Dvojnos GM. Illustrated identification keys to strongylid parasites (Strongylidae: Nematoda) of horses, zebras and asses (Equidae). Vet Parasitol. 2008;156:4-161.

3. Herd RP. The changing world of worms: the rise of the cyathostomes and the decline of Strongylus vulgaris. Compend Contin Educ Vet. 1990;12:732-4

4. Nielsen MK, Olsen SN, Lyons ET, Monrad J, Thamsborg SM. Real-time PCR evaluation of Strongylus vulgaris in horses on farms in Denmark and Central Kentucky. Vet Parasitol. 2012;190:461-6.

5. Kaplan RM, Nielsen MK. An evidence-based approach to equine parasite control: It ain't the 60s anymore. Equine Vet Educ. 2010;22:306-16.

6. Nielsen MK, Mittel L, Grice A, Erskine M, Graves E, Vaala W, et al. AAEP Parasite Control Guidelines. 2019. https://aaep.org/sites/default/files/ Guidelines/AAEPParasiteControlGuidelines.pdf. Accessed 12 Feb 2019.

7. Kaplan RM. Anthelmintic resistance in nematodes of horses. Vet Rec. 2002;33:491-507.

8. Kaplan RM, Vidyashankar AN. An inconvenient truth: Global worming and anthelmintic resistance. Vet Parasitol. 2012;186:70-8.

9. Nielsen MK. Sustainable equine parasite control: perspectives and research needs. Vet Parasitol. 2012;185:32-44.

10. Kumar S, Garg R, Kumar S, Banerjee PS, Ram H, Prasad A. Benzimidazole resistance in equine cyathostomins in India. Vet Parasitol. 2016;218:93-7.

11. Bellaw JL, Krebs K, Reinemeyer CR, Norris JK, Scare JA, Pagano S, et al. Anthelmintic therapy of equine cyathostomin nematodes-larvicidal efficacy, egg reappearance period, and drug resistance. Int J Parasitol. 2018;48:97-105.

12. Kaplan RM, Klei TR, Lyons ET, Lester G, Courtney CK, French DD, et al. Prevalence of anthelmintic resistant cyathostomes on horse farms. J Am Vet Med Assoc. 2004;225:903-10.

13. Lestera HE, Spanton J, Stratford CH, Bartley CH, Morgan ER, Hodgkinson $J$ E, et al. Anthelmintic efficacy against cyathostomins in horses in Southern England. Vet Parasitol. 2013;197:189-98.

14. Traversa D, Samson-Himmelstjerna G, Demeler J, Milillo P, Schürmann $\mathrm{S}$, Barnes $\mathrm{H}$, et al. Anthelmintic resistance in cyathostomin populations from horse yards in Italy, United Kingdom and Germany. Parasit Vectors. 2009;2:S2.

15. Balicka-Ramisz AK, Ramisz AZ. Benzimidazol resistance in nematode parasites in domesticated animals in north-west part Poland. Electron. J Pol Agric Univ. 1999; 2.

16. Borgsteede FHM, Dvojnos GM, Kharchenko VA. Benzimidazole resistance in cyathostomes in horses in the Ukraine. Vet Parasitol. 1997;68:113-7.

17. Lassen B, Peltola SM. Anthelmintic resistance of intestinal nematodes to ivermectin and pyrantel in Estonian horses. Vet Parasitol. 2012;188:294-300.

18. Osterman Lind E, Kuzmina T, Uggla A, Waller PJ, Höglund J. A field study on the effect of some anthelmintics on cyathostomins of horses in Sweden. Vet Res Commun. 2007;31:53-65.

19. Vyšniauskas A, Kaziūnaitė V, Kharchenko VA, Pereckienė A, Tolliver SC, Lyons ET. Determining anthelmintic-resistance of cyathostomes using anthelmintics from two drug classes. Medycyna Wet. 2006;62:883-6.

20. Traversa D, Castagna G, Samson-Himmelstjerna G, Meloni S, Bartolini R, Geurden T, et al. Efficacy of major anthelmintics against horse cyathostomins in France. Vet Parasitol. 2012;188:294-300.

21. Samson-Himmelstjerna G, Fritzen B, Demelera J, Schürmann S, Rohn K, Schnieder T, et al. Cases of reduced cyathostomin egg-reappearance period and failure of Parascaris equorum egg count reduction following ivermectin treatment as well as survey on pyrantel efficacy on German horse farms. Vet Parasitol. 2007;144:74-80.
22. Geurden T, Doorn D, Claerebout E, Kooyman F, Keersmaecker S, Vercruysse J, et al. Decreased strongyle egg re-appearance period after treatment with ivermectin and moxidectin in horses in Belgium, Italy and The Netherlands. Vet Parasitol. 2014;204:291-196.

23. Tzelos T, Barbeito JS, Nielsen MK, Morgan ER, Hodgkinson JE, Matthews JB. Strongyle egg reappearance period after moxidectin treatment and its relationship with management factors in UK equine populations. Vet Parasitol. 2017;237:70-6.

24. Cain JL, Foulk D, Jedrzejewski E, Stofanak H, Nielsen MK. The importance of anthelmintic efficacy monitoring: results of an outreach effort. Parasitol Res. 2019;118:2877-83.

25. Wyk JA. Refugia-overlooked as perhaps the most potent factor concerning the development of anthelmintic resistance. Onderstepoort J Vet Res. 2001;68:55-67.

26. Matthews JB. An update on cyathostomins: antihelmintic resistance and worm control. Equine Vet Educ. 2008;20:552-60.

27. A Guide to the Treatment and Control of Equine Gastrointestinal Parasite Infections. ESCCAP Guideline. 2019. https://www.esccap.org/uploads/ docs/70ep8j2z_0796_ESCCAP_Guideline_GL8_v8_1p.pdf Accessed 12 Feb 2019

28. Coles GC, Bauer C, Borgsteede FH, Geerts S, Klei TR, Taylor MA, et al. World Association for the Advancement of Veterinary Parasitology (W.A.A.V.P.) methods for the detection of anthelmintic resistance in nematodes of veterinary importance. Vet Parasitol. 1992;44:35-44.

29. Lyndal-Murphy M, Swain AJ, Pepper PM. Methods to determine resistance to anthelmintics when continuing larval development occurs. Vet Parasitol. 2014;199:191-200.

30. Lithuanian Equestrian Federation http://www.equestrian.lt/ Accessed 12 Feb 2019.

31. Roepstorff A, Nansen P. Epidemiology, diagnosis and control of helminth parasites of swine. Animal Health Manual. 1998:161.

32. Relf VE, Lester HE, Morgan ER, Hodgkinson JE, Matthews JB. Anthelmintic efficacy on UK Thoroughbred stud farms. Int J Parasitol. 2014;44:507-14.

33. Baermann G. Eine einfache Methode zur Auffindung von Ankylostomum (Nematoden) Larven in Erdproben. Tijdschr Diergeneeskd. 1917;57:131-7.

34. Ministry of Agriculture, Fisheries and Food (MAFF). Manual of veterinary parasitological laboratory techniques 1986. Reference Book 418.

35. Cernea M, Carvalho LMM, Cozma V, Cernea I, Raileanu S, Silberg R, et al. Atlas of diagnosis of equine strongylidosis. Edutura Academic Pres. 2008. p. 120.

36. Samson-Himmelstjerna G. Anthelmintic resistance in equine parasitesdetection, potential clinical relevance and implications for control. Vet Parasitol. 2012;185:2-8.

37. Duncan JL, Love S. Preliminary observations on an alternative strategy for the control of horse strongyles. Equine Vet J. 1991;23:226-8.

38. Buzatu MC, Mitrea IL, Miron L, Ionita M. Efficacy of two anthelmintic products on strongyles in horses from stud farms in Romania. Agric Agric Sci Procedia. 2015;6:293-8.

39. Gomez HH, Georgi JR. Equine helminth infections: control by selective chemotherapy. Equine Vet J. 1991;23:198-200.

40. Nielsen MK, Haaning N, Olsen SN. Strongyle egg shedding consistency in horses on farms using selective therapy in Denmark. Vet Parasitol. 2006;135:333-5.

41. Keidane D, Ozola G, Ilgaza A. Ivermectin resistance of horse digestive strongyles. 26th NJF Congress: Agriculture for the Next 100 Years 27-29 of June, 2018

42. Zak A, Siwinska N, Slowikowska M, Borowicz H, Kubiak K, Hildebrand J, et al. Searching for ivermectin resistance in a Strongylidae population of horses stabled in Poland. Vet Rec. 2017;13:210.

43. Edward CL, Hoffmann AA. Ivermectin resistance in a horse in Australia. Vet Rec. 2008;162:56-7.

44. Lyons ET, Tolliver SC, Ionita M, Lewellen A, Collins SS. Field studies indicating reduced activity of ivermectin on small strongyles in horses on a farm in Central Kentucky. Parasitol Res. 2008;103:209-13.

45. Nareaho A, Vainio K, Oksanen A. Impaired efficacy of ivermectin against Parascaris equorum, and both ivermectin and pyrantel against strongyle infections in trotter foals in Finland. Vet Parasitol. 2011;182:372-7.

46. Kooymans FNJ, Doorn DCK, Geurden T, Mughini-Gras L, Ploeger HW, Wagenaar JA. Species composition of larvae cultured after anthelmintic treatment indicates reduced moxidectin susceptibility of immature Cylicocyclus species in horses. Vet Parasitol. 2016;227:77-84. 
47. Lyons ET, Tolliver SC, Collins SS. Probable reason why small strongyle EPG counts are returning 'early' after ivermectin treatment of horses on a farm in Central Kentucky. Parasitol Res. 2009;104:569-74.

48. Traversa D, Klei TR, lorio R, Paoletti B, Lia RP, Otranto D. Occurence of anthelmintic resistant equine cyathostome populations in central and southern Italy. Prev Vet Med. 2007;82:314-20.

49. Lyons ET, Drudge JH, Tolliver SC. Studies of the development and chemotherapy of larvae of Parascaris equorum (Nematoda: Ascaridoidea) in experimentally and naturally infected foals. J Parasitol. 1976;62:453-9.

\section{Publisher's Note}

Springer Nature remains neutral with regard to jurisdictional claims in published maps and institutional affiliations.
Ready to submit your research? Choose BMC and benefit from:

- fast, convenient online submission

- thorough peer review by experienced researchers in your field

- rapid publication on acceptance

- support for research data, including large and complex data types

- gold Open Access which fosters wider collaboration and increased citations

- maximum visibility for your research: over $100 \mathrm{M}$ website views per year

At BMC, research is always in progress.

Learn more biomedcentral.com/submissions 